\title{
PENGARUH LINGKUNGAN KERJA TERHADAP KINERJA KARYAWAN
} BADAN NARKOTIKA NASIONAL PROVINSI JAWA BARAT

\author{
Rika Omala Agusta \\ Romat Saragih \\ Prodi Administrasi Bisnis, Fakultas Komunikasi Bisnis, Universitas Telkom \\ rikaomala5@gmail.com \\ Prodi Administrasi Bisnis, Fakultas Komunikasi Bisnis, Universitas Telkom \\ saragih@ypt.or.id
}

\begin{abstract}
ABSTRAK
An organization is synonymous with performance, which is defined as a measure of where an organization is success in achieving the target or not, in the province of West Java BNN in 2017 whose activities realized only reached 54.25\%. One of the external factors that can influence is the work environment, it shows that BNN province of West Java has a working environment can create a disgruntled employee.This study was conducted to determine the effect of the work environment on employee performance. The method used in this research is quantitative. Using multiple linear regression with SPSS Ver.23 as data processing tools. From the data processing showed the physical work environment affects $33.1 \%$ and non-physical work environment has a greater influence second known $43.2 \%$ a significant impact on employee performance. It was concluded that the effect on the performance of employees in the province of West Java BNN is a nonphysical work environment, because BNN itself has activities associated with various organizations outside the office.
\end{abstract}

Keywords: Physical Work Environment, Non-Physical Work Environment, Employee Performance

\section{PENDAHULUAN}

Pada Era Generasi Millenial saat ini situasi di tempat kerja telah menantang batas-batas tradisional, sekarang kehidupan sosial sudah semakin berkembang dan berubah sangat pesat terutama dalam hal teknologi yang menuntut perusahaan untuk melakukan perubahan dan mempertahankan aset yang dimilikinya. Salah satu aset yang berharga yang dimiliki perusahaan adalah sumber daya manusia (Setiani, 2013: 38). Sumber daya manusiasebagai salah satu aset organisasi yang dituntut mampu menghasilkan nilai tambah (added value), bersifat jarang memiliki (unique), sulit untuk ditiru (imperfectly imitated), tidak tergantikan sumber daya lain (non-substitutable), dan dapat menciptakan nilai (value creation)(Wardhana，2014: 1).Kualitas kinerja sumber daya manusia memiliki peran besar dalam mencapai targetorganisasi, oleh karena itu organisasi dituntut untuk berusaha untuk meningkatkan kinerja karyawan. evaluasi kinerja karyawan Badan Narkotika Nasional Provinsi (BNNP) 
Jawa Barat dilakukan dengan melihat sejauh mana karyawan dapat memenuhi target kinerja, baik dalam kualitas dan kuantitas dan sejauh mana karyawan memiliki kompetensi yang diharapkan oleh organisasi. kinerja karyawan dapat dilihat salah satunya dengan terealisasinya berbagai kegiatan yang telah ditargetkan. Lingkungan kerja merupakan salah satu faktor dari luar (external) yang dapat mempengaruhi kinerja seorang karyawan, dimana pada dasarnya salah satu aspek yang sangat harus diperhatikan adalah kenyaman lingkungan kerja itu sendiri. Menurut pendapat yang dikemukakan oleh Visher dalam jurnal Sadegi \& Naharuddin (2013:67) kenyamanan fungsional dapat didefinisikan sebagai tingkat dimana karyawan dapat melaksanakan tugas mereka dalam faktor lingkungan keja saat ini. Pendapat lain dijelaskan oleh (Sunyoto, 2013:10) bahwa kondisi kerja merupakan keadaan tenaga kerja sebagai akibat dari kebijaksanaan yang diambil oleh organisasi demi untuk kesejahteraan tenaga organisasi .Tujuan dari penelitian ini adalah untuk mengetahui dan menganalisis bagaimana pengaruh lingkungan kerja terhadap kinerja karyawan BNNP Jawa Barat.

\section{Manajemen Sumber Daya Manusia (MSDM)}

Manajemen sumber daya manusia merupakan ilmu dan seni yang mengatur hubungan dan peranan tenaga kerja agar efektif dan efisien membantu terwujudnya tujuan perusahaan, karyawan, dan masyarakat (Hasibuan, 2018,10). Menurut (Sinambela, 2016:7) Manajemen Sumber Daya Manusia (MSDM) adalah pendayagunaan, pengembangan, penilaian, pemberianbalas jasa, dan pengelolaan individu anggota organisasi atau kelompok pekerja. Dapat disimpulkan bahwa manajemen sumber daya manusia adalah segala kegiatan dan upaya untuk meningkatkan produktivitas dan kualitas karyawan dalam melakukan pekerjaan yang ditugaskan, manajemen sumber daya manusia juga merupakan suatu pengelolaan sumber daya manusia akan suatu perusahaan secara efektif dan efisien agar dapat membantu terwujudnya tujuan dan target dari perusahaan.

\section{Kinerja Karyawan}

Menurut Kasmir (2016: 208), yang menggambarkan kinerja dapat diukur dari beberapa aspek, yaitu: kualitas, kuantitas, ketepatan waktu, efektivitas biaya, pengawasan, dan hubungan antara individu. Menurut Kashmir (2018: 182) adalah hasil dari kinerja dan perilaku kerja yang telah dicapai dalam menyelesaikan tugastugas dan tanggung jawab yang diberikan dalam jangka waktu tertentu. Menurut Fahmi (2016: 176), semua hasil 
yang diperoleh oleh organisasi yang baik organisasi memiliki sifat berorientasi pada keuntungan dan tidak berorientasi pada keuntungan yang dihasilkan selama periode waktu. Satu periode adalah persis apa yang menjadi patokan dalam menentukan kinerja perusahaan.

\section{Lingkungan Kerja}

Menurut Sedarmayanti (2011: 26) yang mencantumkan jenis lingkungan kerja terbagi menjadi 2 lingkungan kerja fisik adalah semua keadaan benda-benda fisik yang ada di sekitar tempat kerja yang dapat mempengaruhi karyawan baik secara langsung maupun tidak langsung dan lingkungan kerja non fisik semua keadaan yang terkait dengan hubungan kerja. Menurut Sunyoto (2013: 11-15) untuk mengukur lingkungan kerja fisik, ada beberapa indikator yang menyala, kebisingan, suhu, ruang yang dibutuhkan, pewarnaan, dan keamanan. Sementara itu, menurut Sedarmayanti (2011: 27) variabel lingkungan kerja non-fisik dapat diukur dengan indikator seperti hubungan atasan dan bawahan, hubungan bawahan dengan atasan, hubungan komunikasi antara karyawan.

\section{Hubungan Antara Lingkungan Kerja} dan Kinerja Karyawan

Berdasarkan teori kepuasan yang dapat dikemukakan oleh Frederick Herzberg dalam Leblebici (2012) maka dapat dikatakan bahwa salah satu faktor yang dapat mempengaruhi kepuasan kerja karyawan adalah lingkungan kerja fisik dan non fisik. Lingkungan kerja memiliki peranan penting bagi karyawan di tempat kerja yang dapat memengaruhi kinerja termasuk keinginan karyawan untuk bekerja.

Gambar 1

\section{Kerangka Pemikiran}

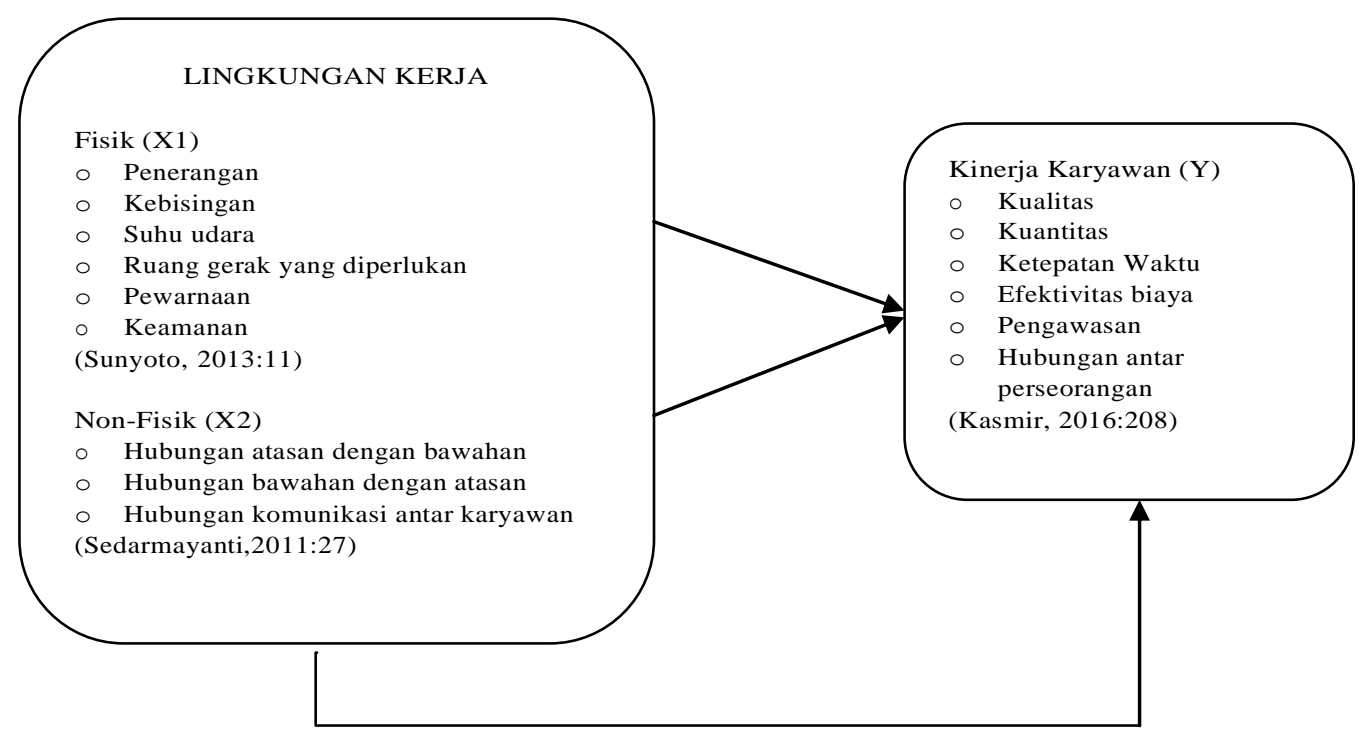

Sumber: Data Olahan Peneliti 
Metode Penelitian

Penelitian ini menggunakan metode kuantitatif dengan jenis penelitian deskriptif dan kausal. Penggunaan metode kuantitatif dalam penelitian ini dilakukan sesuai dengan tujuan penelitian dan menjawab hipotesis penelitian yang telah dirumuskan, yaitu untuk mengetahui pengaruh lingkungan kerja terhadap kinerja karyawan Badan Narkotika Nasional Provinsi Jawa Barat. Hal ini sesuai dengan definisi metode penelitian kuantitatif, yaitu metode tradisional, karena metode ini sudah lama digunakan sehingga sudah mentradisi sebagai metode untuk penelitian (Sugiyono, 2018: 7).Metode ini disebut metode kuantitatif karena data penelitian berupa angka-angka dan anlisis menggunakan statistik. Pengukuran variabel dalam penelitian ini menggunakan skala ordinal.

Sampel adalah bagian dari jumlah dan karakteristik yang dimiliki oleh populasi (Sugiyono, 2018: 81). Menurut (Arikunto, 2012: 104) jika jumlah populasinya kurang dari 100 orang, maka jumlah sampelnya diambil secara keseluruhan, tetapi jika populasinya lebih besar dari 100 orang, maka bisa diambil $10-15 \%$ atau $20-25 \%$ dari jumlah populasinya. Hal ini disebabkan pertimbangan partisipasi, yaitu karyawan Badan Narkotika
Nasional Provinsi Jawa Barat yang diperoleh 92 orang atau $<100$ orang. Teknik analisis data yang digunakan untuk menjawab pernyataan masalah atau menjawab hipotesis yang dirumuskan dalam penelitian ini adalah analisis deskriptif dan analisis regresi liniear berganda. Analisis ini digunakan untuk mengetahui hubungan antara dua atau lebih variabel independen $(\mathrm{X} 1, \mathrm{X} 2$, $\mathrm{X} 3, \mathrm{X} 4 \ldots \mathrm{Xn})$ terhadap variabel dependen (Y) secara serentak atau bersamaan(Indrawati, 2015: 188).

\section{Hasil Penelitian}

\section{Hasil Analisis}

Hasil analisis negara penelitian ini bahwa mayoritas responden adalah laki-laki. Pada Badan Narkotika Nasional Provinsi Jawa Barat didominasi oleh karyawan laki-laki. Hal ini menunjukkan bahwa jumlah laki-laki lebih banyak dibandingkan perempuan. Menurut Robbins (2015:29) tidak memiliki perbedaan pria dan wanita yang konsisten dalam kemampuan memecahkan masalah, kemampuan analitis, motivasi, dorongan kompetitif, kemampuan belajar dan kemampuan bersosialisasi. Menurut Hartatik (2014: 66) pendidikan dengan berbagai program memiliki peran penting dalam proses mendapatkan dan meningkatkan kualitas kemampuan profesional individu. Ini berarti bahwa semakin tinggi pendidikan semakin baik kualitas 
kerja suatu karyawan. Pada Badan

Narkotika Nasional Provinsi Jawa Barat didominasi oleh latar belakang pendidikan S1. Dengan demikian tingkat pendidikan karyawan pada Badan Narkotika Nasional Provinsi Jawa Barat cukup memadai. Menurut Badriyah (2015:196), pengembangan karyawan sebagian besar terjadi melalui pengalaman jabatan atau lamanya bekerja. Karyawan Badan Narkotika Nasional Provinsi Jawa Barat didominasi oleh karyawan 6-10 tahun. Dengan demikian Badan Narkotika Nasional Provinsi Jawa Barat memiliki karyawan yang dominan yang masa kerja cukup lama. Dengan komposisi karyawan didominasi di atas 40 tahun sebanyak 40\% adalah usia yang cukup ideal dalam melaksanakan tugas yang diberikan kepada karyawan di Badan Narkotika Nasional Provinsi Jawa Barat. Menurut (Robbins, 2015:28) pekerja dengan usia yang tua mempunyai pengalaman, ertos kerja yang kuat, dan komitmen terhadap mutu.

Skor yang diperoleh oleh variabel Lingkungan Kerja Fisik (X1) adalah 3740 atau $67,6 \%$ berada dalam kategori cukup baik dan Lingkungan Kerja Non Fisik adalah 2268 atau 82,1\% berada dalam kategori baik.Sedangkan skor yang diperoleh Karyawan variabel Kinerja adalah 4664 atau $77,3 \%$ Dengan demikian Kinerja Karyawan variabel (Y) adalah dalam kategori baik.

Tabel 1

Analisis Regresi Linear Berganda

\begin{tabular}{|c|c|c|c|c|c|c|}
\hline \multirow[b]{3}{*}{ Model } & \multicolumn{3}{|c|}{ Coefficients $^{\mathrm{a}}$} & \multirow[b]{3}{*}{$\mathrm{t}$} & \multirow{3}{*}{ Sig. } & \\
\hline & \multicolumn{2}{|c|}{$\begin{array}{l}\text { Unstandardized } \\
\text { Coefficients }\end{array}$} & $\begin{array}{c}\text { Standardiz ed } \\
\text { Coefficient } \\
\text { s }\end{array}$ & & & \\
\hline & B & Std. Error & Beta & & & \\
\hline 1 (Constant) & 1.376 & 0.636 & & 2.164 & & d \\
\hline $\begin{array}{l}\text { Lingkungan } \\
\text { Kerja Fisik }\end{array}$ & & & & & & \\
\hline & 0.331 & 0.084 & 0.382 & 3.935 & & d \\
\hline $\begin{array}{l}\text { Lingkungan } \\
\text { Kerja Non Fisik }\end{array}$ & 0.432 & 0.095 & 0.391 & 4.233 & & d \\
\hline
\end{tabular}

Dari output software SPSS 23 di atas model regresi diperoleh sebagai berikut:

\section{$Y=1,376+0,331 X 1+0,432 X 2$}

a. Hasil menujukkan nilai konstanta a

$(\mathrm{X} 1, \mathrm{X} 2)$ bernilai $0 \quad(\mathrm{Nol})$ maka $=1,376$, yaitu jika kedua variabel kinerja karyawan Badan Narkotika 
Nasional Provinsi Jawa Barat sebesar 1,376.

b. koefisien regresi b berarti bahwa jika variabel Lingkungan Kerja (X1) meningkat sebesar satu satuan, maka Kinerja Karyawan (Y) Badan Narkotika Nasional Provinsi Jawa Barat akan meningkat sebesar 0,331 atau 33,1\% dan variabel Lingkungan Kerja Non Fisik (X2) meningkat sebesar satu satuan, maka Kinerja Karyawan (Y) Badan Narkotika Nasional Provinsi Jawa Barat akan meningkat sebesar 0,432 atau $43,2 \%$. Koefisien regresi positif, yang berarti bahwa Lingkungan Kerja Fisik dan Non Fisik memiliki pengaruh positif terhadap Kinerja Karyawan Badan Narkotika Nasional Provinsi Jawa Barat.

Berdasarkan Tabel 1 di atas, nilai $\mathrm{t}$ hitung Lingungan Kerja Fisik adalah 3,935> t tabel dan nilai signifikansi sebesar 0,000<0,05, Lingkungan Kerja Non Fisik adalah 4,233> t tabel dan nilai signifikansi sebesar 0,000<0,05.Maka H0 ditolak dan H1 diterima. Dengan kata lain terdapat pengaruh signifikan Lingkungan Kerja Fisik dan Non Fisik terhadap KinerjaKaryawan Badan Narkotika Nasionala Provinsi Jawa Barat.

Pada Tabel 2, nilai $\mathrm{F}$ tabel dengan taraf signifikansi $\alpha=5 \%$ dan degree of freedom $(\mathrm{df})=3 ; 89$ adalah 3,10. Pada tabel di atas menunjukkan bahwa nilai $\mathrm{F}$ hitung sebesar 8,268, hal ini dapat diartikan bahwa $\mathrm{F}$ hitung $(8,469)>\mathrm{F}$ tabel $(3,10)$, sehingga H0 ditolak. Dari tabel di atas juga dapat dilihat nilai (Sig) $0,000<0,05$. Dapat disimpulkan bahwa hipotesis penelitian yang menyatakan lingkungan kerja fisik dan lingkungan kerja non-fisik memiliki pengaruh signifikan terhadap kinerja karyawan Badan Narkotika Nasional Provinsi Jawa Barat.

Tabel 2

Analisis Hipotesis Secara Simultan

\begin{tabular}{|c|c|c|c|c|c|}
\hline \multicolumn{6}{|c|}{ ANOVA $^{a}$} \\
\hline Model & \begin{tabular}{|l|} 
Sum of \\
Squares
\end{tabular} & df & $\begin{array}{l}\text { Mean } \\
\text { Square }\end{array}$ & $\mathrm{F}$ & Sig. \\
\hline $\begin{array}{l}1 \text { Regression } \\
\text { Residual } \\
\text { Total }\end{array}$ & $\begin{array}{l}1.035 \\
5.437 \\
6.471\end{array}$ & $\begin{array}{r}2 \\
89 \\
91\end{array}$ & $\begin{array}{l}0.517 \\
0.061\end{array}$ & 8.469 & $.000^{b}$ \\
\hline
\end{tabular}

a. Dependent Variable: Kinerja Karyawan

b. Predictors: (Constant), Lingkungan Kerja Non Fisik, Lingkungan Kerja Fisik

Sumber: Data Olahan Peneliti 
Tabel 3

Analisis Korelasi Pearson

\begin{tabular}{|c|c|c|c|c|c|}
\hline \multicolumn{6}{|c|}{ Model Summary } \\
\hline Model & $\mathrm{R}$ & R Square & $\begin{array}{l}\text { Adjusted } \\
\text { R Square }\end{array}$ & $\begin{array}{l}\text { Std. Error } \\
\text { of the } \\
\text { Estimate }\end{array}$ & $\begin{array}{l}\text { Durbin- } \\
\text { Watson }\end{array}$ \\
\hline & $.400^{\circ}$ & 0.35 & 0.141 & 0.24715 & 1.509 \\
\hline
\end{tabular}

a. Predictors: (Constant), Lingkungan Kerja Non Fisik, Lingkungan Kerja Fisik

b. Dependent Variable: Kinerja Karyawan

Sumber: Data Olahan Peneliti

Berdasarkan tabel di atas, hasil uji koefisien determinasi memberikan hasil nilai $\mathrm{R}$ sebesar 0.400 dan $\mathrm{R} 2$ sebesar 0.35. Hasil tersebut menunjukan bahwa variabel Lingkungan Kerja Fisik (X1) dan Lingkungan Kerja Non-Fisik (X2) memberikan pengaruh sebesar $35 \%$ terhadap Kinerja Karyawan (Y), sedangkan sisanya sebesar $65 \%$ dipengaruhi faktor lain diluar penelitian.

\section{Pembahasan}

Penelitian ini dilakukan di Badan Narkotika Nasional Provinsi Jawa Barat dengan mengambil sampel dari 92 responden yang merupakan karyawan dari Badan Narkotika Nasional Provinsi Jawa Barat. Hasil pengolahan data pada respon responden terhadap variabel lingkungan kerja fisik(X1)secarakeseluruhantermasukdala mkategori cukup baik.Halini dibuktikan dengan nilai keseluruhan yang diperoleh oleh variabel lingkungan kerja fisik(X1) yaitu sebesar 67,6\% yang artinya Badan
Narkotika Nasional Provinsi Jawa Barat memiliki lingkungan kerja fisik yang cukup baik, dari 12 pernyataan yangmemperolehnilaipalingtinggiadalah ketenangan ruangan yang kondusif memudahkan dalam berfikir dengan persentase sebesar 86\%. Hal ini menunjukkan bahwa karyawan Badan Narkotika Nasional Provinsi Jabar akan merasa tenang dan mudah untuk berfikir jika ruangan kondusif. Sedangkan pernyataan yang memiliki nilai terendah ada yaitu pada pernyataan luas rungan tempat bekerja mendukung dalam menyelesaikan tugas dengan presentase sebesar $43,3 \%$, hal ini menunjukan luas ruangan membuat tidak leluasa dalam beraktivitas di kantor.

Variabel lingkungan kerja nonfisik(X2)secarakeseluruhantermasukdala mkategoribaik.Halini dibuktikan dengan nilai keseluruhan yang diperoleh oleh variabel lingkungan kerja non-fisik(X2) yaitu sebesar $82,1 \%$ yang artinya Badan 
Narkotika Nasional Provinsi Jabar memiliki lingkungan kerja non-fisik yang baik, dari 6 pernyataan yangmemperolehnilaipalingtinggiadalah berpartisipasi dalam team untuk menyelesaikan pekerjaan dengan persentase sebesar $86,5 \%$. Hal ini menunjukkan bahwa karyawan Badan Narkotika Nasional Provinsi Jabar selalu saling membantu dalam menyelesaikan pekerjaan. Sedangkan pernyataan yang memiliki nilai terendah ada yaitu pada pernyataan mendapat arahan atasan dalam menyelesaikan tugas kantor dengan presentase sebesar 78,9\%.

Responden mengenai Kinerja Karyawan variabel berada dalam kategori baik yaitu sebesar 77,3\%. Hal ini menunjukkan bahwa karyawan memiliki baik / kinerja tinggi pada Badan Narkotika Nasional Provinsi Jawa Barat. Dimensi dengan skor tertinggi adalah Hubungan antar Perseorangan yang sama dengan $89,7 \%$. Dimensi terendah adalah Kuantitas yang sama dengan $47,1 \%$.

Perhitungan statistik menggunakan bantuan SPSS 23.0 negara perangkat lunak yang Lingkungan Kerja Fisik dan Non Fisik berpengaruh signifikan pada arah positif Kinerja Karyawan Badan Narkotika Nasional Provinsi Jawa Barat. Ini berarti bahwa variabel penelitian memiliki pengaruh langsung terhadap Kinerja KaryawanBadan Narkotika
Nasional Provinsi Jawa Barat. Semakin tinggi variabel Lingkungan Kerja Fisik dan Non Fisik, semakin tinggi Kinerja Karyawan Badan Narkotika Nasional Provinsi Jawa Barat. Berdasarkan hasil estimasi regresi linear berganda, hubungan antara variabel independen dan variabel dependen cukup kuat, yang diungkapkan melalui nilai koefisien korelasi (R) dari 0.400. Untuk selanjutnya, koefisien korelasi digunakan untuk menghitung besarnya koefisien determinasi. Perhitungan koefisien determinasi menjelaskan Lingkungan Kerja Fisik dan Non Fisik memiliki pengaruh ( $\mathrm{R}$ square) dari $35 \%$ pada Kinerja Karyawan Badan Narkotika Nasional Provinsi Jawa Barat. Sedangkan sisanya $65 \%$ dipengaruhi oleh faktor lain.

\section{Kesimpulan}

Berdasarkan hasil penelitian yang telah dilakukan tentang pengaru Lingkungan Kerja Fisik dan Non Fisik terhadap Kinerja Karyawan Badan Narkotika Nasional Provinsi Jawa Barat, maka beberapa kesimpulan yang diperoleh untuk menjawab sejumlah pertanyaan dalam penelitian ini. Kesimpulan yang diperoleh oleh peneliti yaitu KinerjakaryawanBadan Narkotika Nasional Provinsi Jawa Barattermasukdalam kategori baik sebesar $77,3 \%$. Hal ini berarti seluruh karyawan memiliki kinerja yang baik 
dan sesuai dengan standar yang telahditetapkan.Lingkungan kerja fisik dan non-fisik pada Badan Narkotika Nasional Provinsi Jawa Barat termasuk dalam kategori cukup baik bagi lingkungan kerja fisik sebesar $67,6 \%$ dan baik bagi lingkungan kerja non-fisik sebesar $82,1 \%$. Hal ini berarti bahwa karyawan Badan Narkotika Nasional Provinsi Jawa Barat menilai bahwa lingkungan kerja non-fisik lebih baik dari pada lingkungan kerja fisik.Pengaruh lingkungan kerja fisik dan non-fisik terhadap kinerja karyawan Badan Narkotika Nasional Provinsi Jawa Barat, yaitu secara pasrial lingkungan kerja fisik mempunyai pengaruh yang signifikan terhadap kinerja karyawan berpengaruh sebesar $33,1 \%$ sedangkan lingkungan kerja non fisik memiliki pengaruh yang signifikan terhadap kinerja karyawan berpengaruh sebesar 43,2\%. Secara simultan lingkungan kerja fisik dan lingkungan kerja non fisik memiliki pengaruh secara signifikan terhadap kinerja karyawan berpengaruh hanya sebesar 35\% sedangkan sisanya $65 \%$ dipengaruhi oleh variabel lain yang tidak diteliti dalam penelitian ini

\section{Saran}

Saran bagi perusahaan dimulai dari variabel kinerja karyawan, nilai terendah terdapat pada dimensi kuantitas sebesar $47,1 \%$. Nilai tersebut masuk dalam kategori tidak baik, akan tetapi kantor harus tetap meningkatkan. Maka disarankan pada Badan Narkotika Nasional Provinsi Jawa Barat, harus memperhatikan kuantitas pekerjaan yang diberikan kepada karyawan agar sesuai dengan target yang ditetapkan.Variabellingkungan kerja fisik padaBadan Narkotika Nasional Provinsi Jawa Barat,nilai terendah terdapat pada dimensi ruang gerak yang diperlukan sebesar $43,4 \%$. Nilai tersebut masuk dalam kategori tidak baik. Maka dari itu disarankan bagi perusahaan agar menyediakan ruang gerak yang cukup, agar karyawan mendapatkan kenyamanan dan lebih leluasa dalam beraktivitas di kantor.Variabel lingkungan kerja non-fisik padaBadan Narkotika Nasional Provinsi Jawa Barat, nilai terendah terdapat pada dimensi hubungan atasan dengan bawahan sebesar 78,9\%. Nilai tersebut masuk dalam kategori baik. Selain lingkungan kerja fisik, non-fisik juga harus tetap dijaga baik antara atasan dan bawahan maupun rekan kerja agar dapat terjalin hubungan yang positif tanpa adanya miskomunikasi dan juga diharapkan atasan bisa lebih terbuka agar bawahan tidak memiliki keseganan jika ingin menanyakan suatu hal.

\section{Daftar Pustaka}

Arikunto, S. (2012). Prosedur Penelitian Suatu Pendekatan Praktik. Jakarta: Rineka Cipta. 
Badriyah, M. (2015). Manajemen Sumber Daya Manusia, Bandung: CV Pustaka Setia.

Fahmi, I. (2016). Manajemen Sumber Daya Manusia (Teori dan Aplikasi). Bandung: Alfabeta.

Hartatik, I. P. (2014). Buku Praktis Mengembangkan SDM. Yogyakarta: Laksana.

Hasibuan, Malayu S.P. (2016). Manajemen Sumber Daya Manusia. Edisi. Revisi. Jakarta: Penerbit PT Bumi Aksara

Henry, S. (2011). Manajemen Sumber Daya Manusia. Edisi Kedua. Yogyakarta: Bagian Penerbit STIE YKPN.

Indrawati. (2015). Metode Penelitian Kuantitatif. Bandung: Refika Aditama.

Kasmir. (2016). Manajemen Sumber Daya Manusia (Teori dan Praktik). Jakarta: RajaGrafindo Persada.

Kasmir. (2018). Manajemen Sumber Daya Manusia (Vol.4). Jakarta: RajaGrafindo Persada.

Leblebici, D. (2012). Impact of Workplace Quality on Employee's Productivity: Case Study of A Bank in Turkey. Journal of

Business, Economics, \& Finance, 1(1), 38-49.
Naharuddin Nina Munira and Sadegi Mohammad. Factors of Workplace Environment that Affect Employees Performance: A Case Study of Miyazu Malaysia. Limkokwing University of Creative Technology, Malaysia. A case study of Miyazu Malaysia. International Journal of Independent Research and Studies, 2(2), 66-78.

Robbins, S. (2015). Perilaku Organisai.

Jakarata: Salemba Empat.

Sedarmayanti. (2011). Tata Kerja dan Produktivitas Kerja. Bandung: Mandar Maju.

Setiani, B. (2013). Kajian Sumber Daya Manusia dalam Proses Rekrutmen Tenaga Kerja di Perusahaan. Jurnal Ilmiah Widya, 2.

Sugiyono. (2018). Metode Penelitian Kuantitatif, Kualitiatif, dan R\&D. Bandung, Indonesia: Alfabeta.

Sunyoto, D. (2013). Teori, Kuesioner, Dan Proses Analisis Data Perilaku Oraganisasional. Yogyakarta: CAPS

Wardhana, A. (2014). Manajemen Sumber Daya Manusia. Bandung: PT. Karyamanunggal Lithomas. 